\title{
UMA AULA DE HISTÓRIA NÃO NARCÍSICA
}

A NON-NARCISSISTIC HISTORY CLASS

Nilton Mullet Pereira'

Gabriel Torelly ${ }^{2}$

Resumo: Trata-se de um ensaio teórico sobre a aula de História. A partir da disposição inicial de hesitar diante das práticas narrativas modernas, eurocêntricas e, notadamente, narcísicas, o artigo propõe tecer um caminho de desvio. $O$ que requer problematizar a universalidade do regime moderno de historicidade, para, desde uma posição perspectivista, em diálogo com Nietzsche, Viveiros de Castro e Deleuze, pensar uma Aula Tentacular, não narcísica. Nessa aula, cujo conceito é pensado e dramatizado no artigo, questiona-se a limitação do sentido à identidade entre matéria e imaginação, ligando o trabalho do sentido ao impensado. Depreende-se que as ações mais importantes para uma aula não narcísica consistem em hesitar e "estar à espreita" em relação aos modos como acionamos espelhos perceptivos e como tornamos o passado narrativa. O objetivo de criar condições para uma aula não narcísica também parte do diálogo com Bergson, supondo ser possível experimentar "um pouco de tempo em estado puro", insistindo no caráter sempre contingente do tempo bloqueado sob a forma lógica de cenários possíveis. O resultado é uma aula de História por onde escorrem o ilimitado do sentido, a multiplicidade da matéria e a pluralidade das temporalidades de povos, culturas ou modos de vida.

Palavras-chave: Aula não narcísica. Perspectivismo. Aula Tentacular. Temporalidade. Sentido.

Abstract: This article is a theoretical essay about History class and it proposes to create a deviation, from the starting lay of hesitate against modern narrative practices, which are clearly narcissistic and Eurocentric. It requires problematize the historicity modern regime universality to think a "Aula Tentacular", not a narcissistic, from a perspectivist position connected to Nietzsche, Viveiros de Castro and Deleuze. In this class, whose concept is thought and dramatized in this article, the limitation of identity between subject and imagination sense is questioned, connecting senses to something thoughtless. The knowledge was that the most important actions to make a non-narcissistic class are hesitating and "being in the look out" for the ways we start perceptive mirrors and make the past a narrative. The purpose of creating a class which is not narcissist is also related to Bergson, supposing that it is possible to try "a little of time in its pure state", insisting in time as something contingent and blocked by the logic way of possible scenarios. The result of it is a History class full of unlimited sense, multiplicity of the subjects and the folks, culture and lifestyle plurality.

Keywords: Non-narcissistic class. Perspectivism. Aula Tentacular. Temporality. Sense.

Resumen: Este es un ensayo teórico sobre la clase de historia. Desde la disposición inicial a dudar ante las prácticas narrativas modernas, eurocéntricas y, sobre todo, narcisistas, el artículo propone tejer un camino de desviación. Esto requiere problematizar la universalidad del régimen moderno de historicidad, para que, desde una perspectiva de perspectiva, en diálogo con Nietzsche, Viveiros de Castro y Deleuze, se piense en una Clase Tentacular, no narcisista. En esta clase, cuyo concepto es pensado y dramatizado en el artículo, se cuestiona la limitación del sentido a la identidad entre materia e imaginación, vinculando la obra del sentido con lo impensable. Parece que las acciones más importantes para una clase no narcisista son vacilar y "estar atentos" en relación con las formas en que activamos los espejos perceptivos y cómo hacemos narrativa el pasado. El objetivo de crear condiciones para una clase no narcisista parte también del diálogo con Bergson, asumiendo que es posible vivir "un poco de tiempo en estado puro", insistiendo en el carácter siempre contingente del tiempo bloqueado en la forma lógica de los escenarios posibles. El resultado es una clase de Historia a través de la cual fluyen los ilimitados significados, la

\footnotetext{
${ }^{1}$ Doutor em Educação pela Universidade Federal do Rio Grande do Sul e professor adjunto da Universidade Federal do Rio Grande do Sul, da área de Ensino de História. E-mail: niltonmp.pead@gmail.com. Orcid: https://orcid.org/0000-0002-2280-1920.

2 Doctor en Educación por la Universidad Federal de Rio Grande do Sul. Trabaja como investigador en el área de teoría y metodología de la enseñanza de la Historia y en la línea de investigación sobre las filosofías de la diferencia y la educación. E-mail: gabrieltorelly@gmail.com. Orcid: https://orcid.org/0000-0001-5311-8035.
} 
multiplicidad de la materia y la pluralidad de las temporalidades de los pueblos, culturas o formas de vida.

Palabras clave: Clase no narcisista. Perspectivismo. Lección tentacular. Temporalidad. Sentido.

\section{SOB O SIGNO DA HESITAÇÃO}

Este artigo é escrito sob o signo da hesitação. Usualmente entendida por meio de predicados negativos, tais como a falta de segurança, firmeza ou certeza nas ações de agir ou falar, a palavra hesitação, em sua raiz etimológica, remete a um estado de impasse ou irresolução, uma espécie de (não) lugar intervalar, entre-dois, ou simplesmente entre. Mais do que caracterizar a incompletude de um atributo, procuramos pensar a hesitação como a marca de um excesso que resiste às leis de definição e ao esforço categorial. Hesitante seria, então, o modo de expressão que se percebe incapaz de reunir ou absorver a multiplicidade indefinida dos seres em uma forma lógica suficiente. Postula-se, assim, um signo dedicado a desalienar a imagem do pensamento dos seus inibidores dogmáticos e convencionais, vinculando-a, antes, ao infinitivo direito de ir e vir, de não ir "na direção de uma destinação sem já retornar sobre si" (DELEUZE; GUATARRI, 2010, p. 48).

Do ponto de vista teórico, o artigo faz trabalhar a hesitação como a marca característica de um gesto crítico paradoxal. A impassibilidade do gesto crítico, sua hesitação necessária e profícua, diríamos, se deve à impossibilidade de desenvolver-se como "crítica da cultura" (PRADO JR., 2004, p. 248, grifos do autor) sem, paralelamente, circunscrever e delimitar um fundamento ético comum. Incapaz de prescindir da questão do "fundamento"3 e simultaneamente desconfiada em relação à tonalidade arbitrária ou etnocêntrica das questões fundamentais, a atividade crítica se mantém na tensão do entre-dois. Por isso, do ponto de vista teórico, este artigo não se inscreve nem de um lado nem de outro da querela entre relativismo cultural e proselitismo universalista. $O$ que se busca é fazer trabalhar, por meio de uma imaginação relacional perspectivista4, a "estrutura de contraponto" (PRADO JR., 2004, p. 222) que atravessa a própria querela. Assim, diante do paradoxo, situados num eixo ortogonal, propomos ensaiar os efeitos éticos e estéticos de uma certa equivocidade: desconfiar dos universais sem perder de vista os riscos inerentes à supressão dos esteios que os fundamentam.

Ao iniciar sob o signo da hesitação, devemos, em seguida, chegar a um segundo ponto, a aula, ou, ainda, a sala de aula. Normalmente acreditamos saber do que estamos falando quando empregamos a palavra "aula". A "aula" é um objeto a tal ponto sobrecarregado de pressupostos implícitos que adquire uma autoevidência presunçosa. É contra esta presunção auto evidente que pretendemos estabelecer nosso segundo ponto. Assim, interessa-nos argumentar que uma aula, despida de sua constelação retrospectiva de possíveis, guarda algo de impassível e impenetrável, algo que remete à instância do acontecimento (TADEU; CORAZZA; ZORDAN, 2004, grifos nossos). O acontecimento, no sentido estoico

\footnotetext{
3 Trata-se do "primeiro princípio" ou "ato fundador", pelo qual a raiz forte da metafísica ocidental inclina-se para a questão do sentido como "fundamento" e "fundação" do discurso, conforme CASSIN (2005, p. 85-86).

4 O conceito de "perspectivismo", que trabalharemos ao longo do artigo, "irredutível ao relativismo, se dispõe em um eixo ortogonal à oposição entre relativismo e universalismo". Através de analogias construídas e constatadas entre as teses filosóficas de Nietzsche, Leibniz, Deleuze e Whitehead, e conceitos originados de uma análise dos pressupostos cosmológicos da "metafísica da predação", Viveiros de Castro apresenta o perspectivismo, sob roupagem ameríndia, como uma estratégia capaz de expandir e mesmo inverter os limites convencionais da imaginação conceitual antropológica. Em termos perspectivistas, "o mundo é composto por uma multiplicidade de pontos de vista: todos os existentes são centros potenciais de intencionalidade, que apreendem os demais segundo suas próprias e respectivas características ou potências". Nessa abordagem "todos os seres do cosmos são virtualmente pessoas", a "personitude" e a "potencialidade ontológica" importam mais do que listas taxonômicas ou predicações lógicas segundo às quais o estatuto de pessoa ou de humanidade seria propriedade distintiva de um ser Y ou X. Tomado em perspectiva, o “humano" nunca é uma propriedade, mas uma relação. $\mathrm{O}$ antropomorfismo passa a ser um esquema perceptivo partilhado virtualmente pelo tecido relacional que envolve todos os seres, sempre situados numa escala relativa de potência predatória e capacidade tradutória (algo elementar para os povos indígenas). Assim, um "ponto de vista" jamais se confunde com uma opinião individual sobre um fato da natureza, pois ele é sempre um modo de tecer uma relação entre agências móveis e permeáveis, um modo de arriscar-se a criar uma relação. Com a realidade refratada pelo prisma perspectivista, a fórmula mágica do não-narcisismo começa quando uma efetiva historicidade é libertada do monarquismo ontológico e atribuída a todas as coisas, conforme Viveiros de Castro (2015, p.42-47).
}

Rev. Espaço do Currículo (online), João Pessoa, v.13, n.Especial, p. 753-767, dez. 2020. 
que aqui nos interessa, não é nem um ser nem uma propriedade do ser, mas "o que é dito ou afirmado do ser" (BRÉHIER, 2012, p. 33). Extra-ser. Portanto, a cada vez, uma aula exprime-se, sua consistência jamais se resume ao propedêutico, menos ainda à reprodução ou realização de um modelo ideal de conteúdo, didática, aluno e professor. Interessa-nos, assim, mais os diferentes meios de expressar uma aula do que os constrangimentos relativos que definem os limites de sua expressão.

A hesitação é o signo que marca também a fundamentação ética da aula de História ${ }^{5}$ em uma paisagem intelectual caracterizada pela crise do regime moderno de historicidade (HARTOG, 2013). A crise envolve uma perturbação da relação projetiva em direção ao futuro. Independente de caracterizarmos essa crise a partir da ruína das grandes narrativas (LYOTARD, 1997), ou do monopólio narrativo exercido por um capitalismo ecumênico, o seu efeito seria nublar ou sequestrar nossa capacidade de vislumbrar futuros possíveis, afundando a consciência histórica na agonia de um presente autotélico. Desconectado de seu empuxo em direção a um modelo coletivo de futuro projetado, o presente é invadido por uma miríade de elementos desconexos. Diante dessa problemática que constrange o fluxo das relações temporais, como fundamentar o sentido das aulas de História? Ademais, investindo na força de uma tautologia, perguntamos, faz ainda sentido uma atividade crítica que se porta como fundamentação do sentido? Não seria, por outro lado, a atividade crítica um gesto devotado a estilhaçar a questão do fundamento? Dada a hesitação, deveríamos, ao invés de perguntar sobre o sentido da História ensinada, inverter os termos, e perguntar o que quer a História ensinada com o sentido ${ }^{6}$ ?

Cerca de vinte anos após o diagnóstico de Hartog, Frédéric Neyrat (2018, p. 79-90) apresenta-nos linhas complementares para pensar o problema. Segundo Neyrat, o presentismo, epifenômeno daquilo que Gilles Deleuze caracteriza como "sociedade de controle" (DELEUZE, 2013), intensificou-se a tal ponto que a relação com o futuro ${ }^{7}$ já não se baseia somente no bloqueio ou na afasia geral das possibilidades projetivas, mas na proliferação das técnicas de antecipação. Neyrat argumenta que as sociedades de controle tornaram-se clarividentes, antecipatórias, não apenas encerrando, mas colonizando antecipadamente o futuro via contínua projeção de cenários possíveis e incompossíveis. Diante deste modo peculiar de engrenagem entre as dimensões temporais, como pensar as relações que uma aula de História entretece com o tempo? Se se trata de combater a asfixia e a sensação de angústia, geradas pela

\footnotetext{
5 Meinerz et al. (2018) criam a ideia de uma aula como um ambiente marcado por uma "ecologia de saberes", atentando para a ideia de uma abertura nos sentidos possíveis desse lugar.. Além disso, no campo da pesquisa sobre o ensino de História, a ideia de uma aula Caos é abordada como forma de problematizar o que chamamos de colonialidade do tempo (AUTORES, 2018).

6 São abundantes as pesquisas e as publicações que procuram pensar o sentido em uma aula de História, constituindo debates em torno do que ensinar, das estratégias didáticas utilizadas e, também, dos fundamentos de uma aula de História. Monteiro há alguns anos vem desenvolvendo um debate em torno da ideia do ensino de História como "lugar de fronteira" e de que em uma aula de História teríamos um tipo singular de saber, o "saber escolar”, a partir de um diálogo com Forquin, Develay, Lopes (MONTEIRO, 2003).

${ }^{7} \mathrm{O}$ campo do ensino de História, habitado por inúmeras tendências teóricas, tem sido espaço de disputa tanto pelo passado quanto pelo futuro. A ideia de que a aula de História é um espaço de formação de pessoas capazes de problematizar o presente, na perspectiva de construir futuros eticamente responsáveis é bastante recorrente. Certamente, nos tempos atuais, supor que a possibilidade de projetar o futuro nos foi roubada, consiste em um problema de grandes proporções para a pesquisa e para o ensino de História. Não são poucas as publicações do campo que pensam a aula de História como um projeto crítico de construção de futuros melhores, através da crítica profunda e da intervenção no presente. É o caso, por exemplo, do que argumenta a pesquisadora Margarida Dias Oliveira (HISTÓRIA, 2010), ao citar o trabalho histórico e fundador do campo de Elza Nadai (NADAI; LAGOA, 1991, p. 16): “A história pode englobar uma época ou uma vida individual, o estudo de uma cidade ou de uma nação. "Estuda-se história para poder pensar o outro. Para entender a dialética da mudança e da permanência. Ver que a vida não é retilínea. $\mathrm{E}$ que o futuro pode ser diferente do presente. Mais do que entender o passado, estudar a história é trabalhar a diferença, a tolerância", como afirma a professora Elza Nadai. Nesse sentido, a escolha dos conteúdos para serem trabalhados em sala de aula precisa refletir esta forma de pensar a função do ensino de história, ou seja, trabalhar a diferença e a tolerância na formação de cidadãos conscientes da sua história e da história do outro". História: ensino fundamental / Coordenação Margarida Maria Dias de Oliveira. - Brasília: Ministério da Educação, Secretaria de Educação Básica, 2010. 212 p.: il. (Coleção Explorando o Ensino; v. 21).
} 
proliferação cotidiana de cenários fragmentários e de um futuro esconjurado por mecanismos antecipatórios, uma aula poderia ainda ser o espaço onde experimentamos um pouco de "tempo livre" (MASSCHELEIN; SIMONS, 2013)?

Uma falsa alternativa seria argumentar que se trata então de produzir contra cenários, pois assim apenas confirmaríamos ao avesso o mecanismo do planejamento. Recuperar ou ocupar novamente o tempo roubado envolve, antes, uma necessidade primeira de curto circuitar o processo de encenação em si, romper a própria forma do script, "desroteirizar" (NEYRAT, 2018, p. 88) o futuro, e mais uma vez, diríamos, hesitar diante das fixações e dos imobilismos que antecipam a virulência do tempo em imagens apaziguadas. A ideia de que o tempo tem necessidade de uma forma lógica associada é uma vulgata da inteligência espacial, prisioneira do mecanismo "cinematográfico" (BERGSON, 2010a) do pensamento, sobre a multiplicidade qualitativa do tempo em si. Trata-se da armadilha que a epistemologia kantiana nos deixou, ao confundir e sobrepor na sua concepção da experiência humana os níveis empírico e transcendental (PRADO JR., 2004) ${ }^{8}$. Experimentar "um pouco de tempo em estado puro" (BERGSON, $2010 b)^{9}$ seria tomar o caminho inverso e insistir no caráter sempre contingente do tempo bloqueado sob a forma lógica dos cenários possíveis. Tendo em vista essas primeiras observações é que perguntamos: através de que movimentos uma aula de História pode tornar-se capaz de experimentar a matéria do tempo em si, ou melhor, como ela pode arranjar suas operações à luz de uma remodelação da estética transcendental? Ensaiar essa questão envolve rasurar as linhas de nossa imagem narcísica, em especial aquela que fez da temporalidade eurocêntrica o elo sucessivo e evolutivo da teia desde onde construímos relações com o passado, na sala de aula de História e fora dela. É por isso que uma Aula Tentacular ${ }^{10}$ se torna, neste artigo, um modo de criar conceitos para transitar num mundo que ainda não existe: uma aula não narcísica.

Chamemos inicialmente "narcísicas" as operações abscissas e lineares pelas quais enquadramos um fluxo temporal de ordenadas intensivas num dado campo perceptivo. Quando trocamos o automatismo espelhado das operações narcísicas por outro mecanismo, hesitante, atravessado conceitualmente pela presença consistente do outro, é toda a percepção que se redistribui e o feixe temporal de um novo campo problemático se abre para experimentação. Por isso, é necessário lançar mão de novos conceitos (a Aula Tentacular) e da "pedagogia do conceito" (BIANCO, 2002) extrair uma nova forma de atenção (perspectivista) para a sala de aula e sua respectiva capacidade de expressão. Tomada nessa linha, a hesitação é uma pequena discrição que impomos ao sentido que precede o gesto (didático), desdobrando os rigores assertivos do método através das ressonâncias experimentais do conceito. Menos que um método, mais que uma distração, ela funciona como um artifício performativo (ZUMTHOR, 2014) pensado, voltado a captar forças seletivas que nos permitam criar vias de escape em relação às aporias de um discurso crítico paradoxal.

\section{NA TEIA DOS ANTROPOMORFISMOS ESTÉTICOS}

O narcisismo é o artifício político e estético de uma experiência marcada pelos antropomorfismos. Os antropomorfismos estéticos (NIETZSCHE, 2001) nada mais são do que as formas que damos à nossa percepção. Através dos sentidos, medimos a distância que nos liga ou separa do mundo, dos outros e de nós mesmos. Quer dizer que a relação de nossos sentidos com o real é sempre limitada - enxergamos, tocamos, cheiramos, sentimos apenas uma parcela do seu tecido, e a esse limite damos o nome de percepção. A experiência complexa dos sentidos (por isso antropomorfismos é grafado no plural) lança em torno de cada ser uma espécie particular de teia ou de "círculo concêntrico, que lhe é peculiar". No fragmento 117 de Aurora, Nietzsche descreve como a teia da percepção se liga ao funcionamento narcísico: "não há escapatória, não há trilhas ou atalhos para o mundo real! Estamos em nossa teia, nós, aranhas, e, o que quer que nela apanhemos, não podemos apanhar senão justamente o que se deixa

\footnotetext{
8 "Mas qual é o equívoco de Kant? Tudo se passa como se Kant houvesse, no mesmo gesto, descoberto e recoberto a dimensão do transcendental" (PRADO JR., 2004, p. 164-165).

9 Trata-se da concepção, descoberta por Bergson em Matéria e memória, de um "Tempo que é a coexistência de todos os níveis de duração" (DELEUZE, 2013, p. 81).

${ }^{10}$ A expressão "tentacular" é livremente inspirada a partir das produções artísticas de Ali do Espírito Santo. A trajetória do artista pode ser conferida em: https://alidoespiritosanto.wixsite.com/alidoespiritosanto.
}

Rev. Espaço do Currículo (online), João Pessoa, v.13, n.Especial, p. 753-767, dez. 2020. 
apanhar em nossa teia" (NIETZSCHE, 2004, p. 90, grifos do autor). A teia dos antropomorfismos nos convida a uma dupla consideração sobre a natureza da percepção estética. De um lado, sublinha o confinamento dos sentidos ao potencial interno de cada experiência; de outro, aponta para a situação perspectivista de que se trata sempre da nossa teia.

As formas da percepção estética, reforçadas pela continuidade dos hábitos intelectuais, depositamse na arca da memória como estratos ou sedimentos que cristalizam estereótipos e fundamentam narrativas. Aqui a linha entre a experiência estética e a dimensão política se torna tênue, pois aquilo que era diferencial, marca de uma perspectiva, pode querer se fazer passar pela forma lógica de um conceito universal. No cruzamento das linhas o problema se adensa, pois há o risco de atribuir aos "outros" uma marca, um estigma, um tom, até mesmo uma cor, em função das sensações que eles provocam em "nós", criando, assim, uma "falsa positividade inversa" (NIETZSCHE, 2004, p. 91). Se é certo que estamos sempre envolvidos por nossa teia, também é certo que o "outro" não é apenas a forma como convertemos um determinado sujeito em objeto, mas a própria função estruturante que distribui os termos em relação num dado campo perceptivo (DELEUZE, 2015). Projetado como artifício político, o narcisismo possui um forte potencial etnocêntrico, pois a matéria do outro é talhada nos moldes do nosso próprio campo e limitação. Como não sucumbir ao narcisismo, uma vez que os limites de nossa percepção criarão ao que, também por narcisismo, chamamos de outro, um lugar que não é o seu, mas o nosso?

Quem sabe a estratégia da linha não seja sua necessária interrupção? Quem sabe o espelho não deva ser quebrado ou estilhaçado (BELLO; MARQUES, 2017)? E isso se fará tanto por uma política, que se dispõe a interromper a anestesia perceptiva fazendo sucumbir nossos vínculos habituais com o real; quanto por uma estética, que, como a arte e a literatura, nos fará, na própria sala de aula de História, criar modos de expressão que façam desaparecer, ao menos em frações de tempo, o eu e o outro, o vínculo lógico, pragmático e transcendental do pensamento com a exigência de significação (CASSIN, 2005). Desfiando à contrapelo ${ }^{11}$ o novelo da tradição, teríamos, logo, a tarefa concentrada de uma dupla iconoclastia: 1) quebrar o espelho a partir do qual a lei do "mesmo" reflete-se em todas as imagens possíveis; 2) emperrar o empuxo semântico por meio do qual toda palavra encontra seu lugar específico na corrente da significação. Tudo isso parece ser um modo de querer fugir da teia e até mesmo da nossa própria perspectiva.

Entretanto, não é esse nosso objetivo. O ponto onde o narcisismo se torna universal e a narrativa histórica torna-se espelho que reflete o outro unicamente na armadilha da percepção é que são as estruturas da nossa desconstrução, como de resto de muitos outros colegas, desde outras perspectivas teóricas, do campo do ensino de História e da teoria da História, que têm feito tremer as linhas fixas e as imagens espelhadas que nos moldaram por muitos anos ${ }^{12}$. Para isso, abordamos, sob vários ângulos, 0 complexo de nossas relações com a temporalidade. Em especial, com uma noção de passado que, ao contrário do que supõem muitas vezes as operações lógicas evocadas pela narrativa histórica, não passa, não se faz passar, mas coexiste com o presente. Ao tratar de um passado que não passa, que é contemporâneo ao presente na experiência do tempo, passamos a questionar os clichês relativos aos modelos do evolucionismo e apresentamos a necessidade de abordar a coexistência de ontologias e epistemologias, não mais entendidas como lineares e progressivas, de modernos e não modernos, ocidentais e não ocidentais, povos com história e povos sem história, modelos refratários do eu e do outro (SETH, 2013).

Tecer desse modo o novelo do tempo é perceber que os "mundos outros" são contemporâneos

\footnotetext{
${ }^{11}$ Benjamin (1996), nas Teses sobre o conceito de História, especificamente na tese VII, se refere a escovar a história à contrapelo, tarefa do materialista, em relação à cultura em geral.

12 Trata-se de um movimento muito amplo e diverso, do ponto de vista teórico, que se apresenta, neste século, no campo do ensino de História, particularmente, no que diz respeito ao debate em torno da educação das relações étnico-raciais e do gênero. Importante enfatizar que há grande número de trabalhos, artigos, dissertações e teses que, além de pensar sobre os dois temas em questão, problematizam os universalismos e as temporalidades ligadas a uma narrativa histórica moderna e eurocêntrica. Eis alguns exemplos: Moura (2018); Bergamaschi; Gomes (2012); Pereira (2012); Pereira; Araújo (2017); Avila; Nicolazzi; Turin (2019).
} 
ao "mundo mesmo". Isso pode ser entendido de diferentes maneiras, mas a ideia geral é de que não há superação de estágios, algo que implicaria uma sucessão de escalas e ultrapassagens entre o mais e o menos evoluído. O que teríamos, de fato, seria um regime de coexistência complexa, isto é, não apenas dual, entre aquilo que outrora foi considerado o "atrasado" e o "desenvolvido". Não se trata apenas de rechaçar a redução do "atraso" a uma figura única para em seguida reconhecer a sua pluralidade. Tratase de criar condições para pensar um quadro em que o atraso não passa, ele jamais se faz passado ou ultrapassado, pois ele não somente insiste e coexiste no tempo, como é capaz de afrontar diretamente a figura retórica do "avanço", superando e desmontando, em termos éticos, estéticos e epistemológicos, a presunção narcísica envolvida em um modo de ser e pensar colonizador e autocentrado. As diferentes figuras do atraso "não podem mais ser superadas porque nada mais as ultrapassa" (LATOUR, 2013, p.76). Tal problema não se desdobra somente em implicações de ordem política e econômica, mas em questões mais profundas relacionadas aos próprios modos de expressão que dispomos para contar uma história.

Saber-se aranha e hesitar diante dela implica poder, quem sabe, intuir que os outros não se apresentarão como objeto da nossa decifração, senão inseridos numa "escala relativa de potência predatória" (VIVEIROS DE CASTRO, 2015, p. 45), uma vez que são apenas discerníveis num dado campo relacional, perceptivo-perspectivo, desde um presente temporal de onde se produz o discurso histórico. Um fino paradoxo que possui o duplo desse outro: por um lado, objeto da política da designação, que lhe atribui identidade e lhe faz uma cara nas lutas identitárias e afirmativas do presente; por outro lado, uma estética do trabalho do sentido, livre das operações designativas, apartado da matéria sensível que lhe faz ser visto como o outro do mesmo. Tal operação nos fará intuir que a Terra Sem Males dos Guarani (MELIÀ, 1990) não consiste nem em um recanto livre de todo o mal característico do mundo dos brancos, sendo uma sociedade utópica que nos sirva de refúgio de nossa própria iniquidade; nem no ponto de projeção de uma generosidade só possível a povos sem cultura e providos de uma ingenuidade infantil, selvagem, que caracterizaria a alma do Guarani desde o nosso espelho narcísico. Tanto uma quanto a outra solução parecem responder à fina seleção da nossa inteligência, nos aprisionando na teia da ingenuidade estética e fechando-nos à diferença da experiência Guarani.

Isso ocorre porque professores de História se colocaram diante da ideia de que os fatos já não são evidentes por si mesmos, um desafio lançado para a área nos anos 80 e $90^{13}$ e que tem trazido uma série de intercorrências. Ver os fatos como construções nos faz pensar de uma só vez o fato e o valor como indiscerníveis e isso, de modo bastante embaraçoso, parece, contra a nossa vontade, aprofundar nosso narcisismo, mais sútil e difícil de verificar, uma vez que o relativismo pura e simplesmente daria conta de mostrar que, afinal de contas, tudo o que se ensina é relativo a uma determinada percepção do mundo. $\mathrm{O}$ que nos parece generoso, mas nunca nos livrou do narcisismo. Talvez a questão seja o fato de que esse embaraçoso relativismo esteja vinculado a ideia de que o discurso histórico sempre surfaria no duplo da empiricidade e da imaginação histórica, como duas linhas que se estendem ao infinito sem nunca se encontrarem.

$\mathrm{Na}$ esteira dessa embaraçosa situação, o ensino de História assume a consequência de reduzir as possibilidades de criação de sentido desde as tensões entre a matéria e a imaginação, uma vez que tem se esmerado por reafirmar que o sentido só é possível em uma aula de História, quando há identidade entre o conteúdo ensinado e a realidade do aluno. Ora, como já afirmamos, tal noção, bastante comum no campo, reduz as possibilidades de uma aprendizagem ética com o passado e com os outros (povos, culturas, cosmologias, epistemologias, metafísicas ... perspectivas), pois faz a aprendizagem circular sempre em torno de um mesmo, que é o "eu" e suas circunstâncias. Assim concebido, o sentido permanece preso à limitação pragmática de sua natureza linguística, quando interessaria, em termos

\footnotetext{
13 Importante referir pesquisadoras de grande significação para o campo do ensino de História, que publicaram e problematizam a história ensinada que, naquela época, ainda estava povoada pela história dos heróis e pelas narrativas nacionais e dos grandes homens. Esse trabalho fundamental e fundador para o campo teve diversos nomes, destacaremos apenas alguns: CABRINI, Conceição et al. O ensino de História - revisão urgente. São Paulo, Brasiliense, 1986; FONSECA, Selva Guimarães. Caminhos da História Ensinada. Campinas, SP: Papirus, 1993; BITTENCOURT, Maria Circe. Pátria, Civilização e Trabalho - O ensino de história nas escolas paulistas - 1917-1939. São Paulo: Loyola, 1990; NADAI, Elza. O ensino de história no Brasil: trajetória e perspectiva. Revista Brasileira de História. São Paulo. 1993.
}

Rev. Espaço do Currículo (online), João Pessoa, v.13, n.Especial, p. 753-767, dez. 2020. 
ISSN 1983-1579

Doi: 10.22478/ufpb.1983-1579.2020v13nEspecial.53988

http://periodicos.ufpb.br/ojs2/index.php

éticos, destacar o seu aspecto ilimitado (DELEUZE, 2015), pelo qual ele não se relaciona somente com a manifestação de um Eu, mas com o “impensável de sua gênese” (GIL, 2018, p. 445).

\section{A IMAGEM NARCÍSICA}

Essa imagem narcísica parece ter feito parte, sob a forma de uma relação de redução entre o Eu e o Outro, de um certo imaginário da aula de História. Ocorre que esse imaginário se consolidou como teoria, cheia de argumentos e demonstrações, baseado em uma assertiva muito comum: "o sentido da aula de História estaria na aproximação do conteúdo ensinado (um passado recortado em História) com a realidade do aluno (talvez com isso se quisesse dizer sobre as circunstâncias da vida dos alunos no presente do tempo)". Essa máxima, que adquiriu o status de teoria e de verdade quase imutável no campo do ensino de História é, em si mesma, generosa, entretanto, profundamente narcísica. Vamos ver o porquê.

Sob vários aspectos, a noção de que há uma distância entre os conteúdos estudados e a realidade dos alunos tem sustentado a ideia de que só se aprende história quando o estudante consegue criar relações necessárias entre suas circunstâncias temporais e identitárias e o conteúdo ensinado. Mas, queremos argumentar que essa distância só existe se ainda estivermos presos na teia do mundo dos homens brancos que celebram o lucro e a utilidade. Obviamente há conteúdos e modos de expressá-los muito pouco sedutores e pouco provocadores, o que configura um outro problema. O que interessa-nos sublinhar é uma questão de fundo, ou mesmo de fundamento: que a crença na distância entre os conteúdos que ensinamos em história e a chamada realidade dos alunos é uma marca muito forte do nosso narcisismo. Então, essa máxima, essa sentença quase inexoravelmente verdadeira, que habita o campo do ensino de História desde tempos quase imemoriais (isso tende a ser até novecentista, cremos que até mesmo os positivistas acreditavam nela), quase incrivelmente generosa e expressão de um pensamento notadamente revolucionário no campo pedagógico, parecer ser - desde nossa contínua hesitação - narcísica, branca, eurocêntrica.

A proposição em causa decorre da crença de que a aprendizagem em História só é possível e somente produz sentido quando o objeto a ser aprendido está relacionado, leia-se identificado, com a realidade dos alunos. Ou seja, os alunos somente seriam capazes de aprender aquilo que faz sentido para a sua realidade presente e atual ou que permite ativar suas memórias pessoais. O sentido, desse modo, é reduzido, mais uma vez, à identidade. E mais, o sentido somente parece ser possível desde essa ideia, quando há semelhança, quando o conteúdo ensinado parece ser facilmente reconhecível, quando os elementos formais e de razão que constituem o arsenal intelectual do estudante são capazes de perceber e quando as memórias, as emoções e as sensibilidades do aluno permitem estabelecer conexões. Poderíamos muito bem chamar esse movimento de "o logro do sentido", uma vez que ele está circunscrito na semelhança, sendo reativo a tudo o que parece diferença. Ora, antes de tal proposição se mostrar o elemento revolucionário que vai nos libertar da alienação de um passado e de um outro irreconhecível e inexplicável pela nossa narrativa, ela é um modo pouco sofisticado, mas poderoso, de aprisionar a produção do sentido e, ainda mais, um modo de aprofundar o nosso habitual narcisismo, uma vez que tudo o que cercará a vida de um aluno em uma aula de História será ele mesmo, sua identidade e os sentidos (de mundo, de relações, de vida) possíveis e limitados por ele mesmo. E aí nos perguntamos: não seria trabalho de uma aula de História a diferença e o ilimitado do sentido? Não seria a aula de História o lugar do espelho estilhaçado? E não seria a aprendizagem em História um modo de aprender com o estilhaço, sendo essa aprendizagem um modo de liberdade em relação à singularidade do outro? Esta constante identificação não seria um modo de manter e aprofundar o nosso narcisismo?

É nosso objetivo, portanto, sublinhar que a crença na existência de uma distância entre o "conteúdo ensinado" e a "realidade do aluno" está baseada numa série de pressupostos narcísicos. Doravante, haveria ainda outro ângulo pelo qual a questão merece ser problematizada, que é o da qualificação da distância, isto é, a compreensão de que a distância não marca apenas uma dificuldade intransponível ao intelecto, mas um convite sedutor, o que nos permite pensar que é justamente pelo incremento da distância entre "realidade" e "conteúdo" que se aprende. Nas antípodas do desejo de semelhança, a sedução do longínquo. Quem é o aprendiz? É aquele que se mantém fixo ao caráter do que 
já conhece, reconhecendo somente o valor das coisas que recolhe nos limites das imagens familiares? Não seria o aprendiz uma espécie de ser público e alado, capaz de transitar, viajar, afrontar os limites perceptivos, precisamente para aprender algo novo a respeito da teia na qual tece relações entre identidade e diferença ${ }^{14}$ ? As duas atitudes parecem possíveis. Talvez sejam mesmo duas diferentes políticas ou curvas de aprendizagem, uma delas valorizando um sentido local, a outra incitando o sentido ao impensado.

Pensar a escola e a Educação no âmbito de uma questão pública envolve a compreensão de um argumento não habitual. O caráter não habitual reside no desafio de pensar contra o conjunto de regras adquiridas, contra as presunções de sentido que aprendemos a confundir com a própria existência. Em casa, em família, ou em algum outro lócus específico onde aprendemos a identidade, somos habituados a confundir a particularidade de nossa existência (nossa realidade) com alguma forma de vida determinada. É da alçada do "público" desfazer os termos dessa confusão (MASSCHELEIN; SIMONS, 2013). Ao adentrar na arena pública, o pacote de regras particular que compõe a densidade ontológica de uma forma de vida determinada é precisamente o que é descompactado. A escola e a Educação são os nomes que atribuímos a esse lugar nenhum onde as particularidades que compõem cada forma de vida são vazadas e chamuscadas pelo calor da matéria viva. O caráter público consiste na capacidade de furar o inchaço identitário e fundar o espaço ético de trânsito onde a igualdade é verificada. Transitar envolve abismar-se na sensação de não ser ainda uma pessoa e de não ter ou estar em nenhum lugar. Nesse aspecto, a escola pública não é lugar para se sentir em família, em casa, ou em sintonia com alguma particularidade de caráter ou temperamento, mas o entreposto radical onde a suspensão das regras determinadas que envolvem uma existência qualquer cria uma superfície de contato com o ilimitado do sentido.

Abaixo, uma cena de sala de aula fabulada - esse modo que possuímos de mostrar e explorar o que acontece em uma aula de História - permitirá mostrar como o trabalho do sentido está intimamente relacionado, quando se pensa uma aula de História não narcísica, à abertura ao impensado, o que quer dizer que as ações mais importantes dos encontros com os outros são hesitar e "estar à espreita" em relação ao modo como tornamos o passado narrativa. Trata-se de mais um dia de trabalho. O professor universitário $\mathrm{F}$. se encaminha para assistir mais um de seus alunos (G.) em exercício de estágio curricular obrigatório. Tudo parece ocorrer tranquilamente. Até que algo acontece. Eis o buraco criado por Deus, assinalando a ruína da narrativa e a abertura para o ilimitado do sentido.

F. começara a assistir a aula atravessado pela impressão de que a memória muitas vezes podia funcionar em sintonia com uma estrutura artificial, um engenho intelectual, cuja invocação cotidiana se destina a colocar ordem nos retalhos do passado. Há tempos $F$. se pergunta sobre as funções da memória e essas perguntas acompanham-no ao entrar mais uma vez em uma sala de aula para acompanhar os estágios curriculares. O tempo, o devir, a memória e as formas fixas que a narrativa lhes atribui.

G. escrevia no quadro duas palavras compostas e de difícil decifração para os alunos. Entre as duas palavras, desenhava alguns sinais que indicavam uma espécie de mudança e em seguida iniciava sua narrativa. Silêncio. "A época moderna se caracteriza pela transição entre o teocentrismo e o antropocentrismo".

Provocado pelo teor da afirmação, F. mergulha novamente naquela impressão inicial. Ao relacionar-se desse modo com a memória, o que se passa em nossa percepção? O que ocorre aos retalhos que de outro modo poderiam vagar dispersos sem chegar a formar parte de uma constelação referencial? Será que pedaços do passado poderiam nos atingir em cheio, caso não fossem previamente ordenados por uma estrutura? Perguntas de um observador de estágios.

Aproveitando-se de uma antiga e ainda produtiva estratégia didática, G. desdobrou aquelas duas palavras difíceis em três, operando um verdadeiro milagre diante dos olhos dos alunos. "Deus", o "Homem" e o "Centro". Perplexo, F. observa que mesmo na balbúrdia extraordinária que é uma sala de aula, a pronúncia da palavra "Deus" produziu uma paralisia momentânea da dispersão geral, capturando as

14 "O aluno aprende, diria o Deleuze-Guattari de Mil platôs e de Anti-Édipo, quando se conecta de maneira arepresentativa e descodificada com seu mestre" (BIANCO, 2002, p. 16, grifos do autor). 
atenções. Deus foi a brecha do acontecimento, uma fagulha de expressão. Por alguns instantes, os alunos estranhamente querem saber o que G. tem a dizer. F. se pergunta se aquilo que ocorreu quando $G$. pronunciou a palavra "Deus" não invalida o sentido assertivo da própria explicação registrada no quadro (Teocentrismo ---> Antropocentrismo).

G. segue com a explicação. Para cada época haveria um centro; e esse centro seria ocupado pela referência a uma determinada forma lógica; uma viria antes, a outra, depois. De um Deus central passa-se a um Homem centrado e isso, de acordo com o discurso bem articulado de G., estaria repleto de consequências para os nossos modos de ser atuais. Assim subdividia-se também o que convencionou-se chamar de "Idade Média" e "Idade Moderna". As Índias, Cristóvão Colombo, as Grandes Navegações, Martinho Lutero, o Renascimento eram outras palavras importantes que eram chamadas a contribuir para a formação de um grande divisor de águas, marcador da irreversibilidade entre um antes e um depois, um dentro e um fora, um nós e um eles.

O sucesso daquela aula parecia depender de que ficassem bem marcadas as diferentes passagens e o caráter lógico das transições, o que seguramente estimula a capacidade dos alunos de se orientar no tempo. Havia uma ligação entre os fragmentos (fragmento Deus e fragmento Homem) e dessa ligação avança-se para uma atribuição de sentido. Eis o percurso da aula. Mas $F$. não pode deixar de ficar perplexo com aquele buraco aberto por "Deus". Ali parecia haver uma chance... Algo ocorria ali. Por um momento as cartas da memória pareciam se embaralhar, embora justamente para nomear esse "algo" Ihe falte a palavra. O que mesmo? $O$ que seria aquele algo inexistente e, todavia, capaz de ativar as energias em jogo? Talvez fosse o próprio sentido, rebelando-se contra o artifício narrativo, mostrando-se em disputa, à mercê dos encontrões do imaginário. Talvez fosse mesmo o tempo, o próprio tempo, esquivando-se à estrutura e se mostrando como questão.

Tudo se passa como se Deus tivesse aí, nessa rachadura que fendeu o cenário planejado de uma aula de História, se desencontrado com o mesmo, com a semelhança e com a identidade. Provocadas pelo desencontro, forças estranhas escorrem pelas bordas da sala, solapam os contornos de estágios e idades, friccionam e giram as transições, desconfiam dos limites dos "eus" e dos "outros". Nesse script perturbado de temporalidade em transe, prepara-se o terreno para devires e tremores. A hesitação, agora palpável, em relação ao espelho narcísico, abre a "boca" da sala de aula, movendo as articulações do sentido, para a entrada da Terra Sem Males dos Guarani, o que ocorre de modo incrivelmente inusitado, já que a aula queria se situar na passagem de duas grandes ficções, a Idade Média e a Idade Moderna, e já que a causa da abertura fora justamente Deus, o Deus judaico-cristão. A linha quebrada. $O$ espelho estilhaçado. O sentido de uma aula de História pode não estar preso para sempre nessa ordem de dispositivos antropomórficos e o "sucesso" de uma aula pode bem estar marcado pela produção de uma estranha abertura e pela proliferação de uma série de paradoxos que anulam os efeitos de qualquer palavra final.

\section{TEMPO E TEMPORALIDADE: desfiando o evolucionismo nosso de cada dia}

O evolucionismo, aplicado às ciências humanas e sociais (o que é profundamente diferente da alta complexidade envolvida na teoria da evolução), criou uma espécie de atalho epistemológico, cujos efeitos éticos, práticos e políticos manifestam-se de maneira plural. Trata-se de um atalho, pois através de uma simplificação transposta, ele livra-nos do difícil exercício de pensar a multiplicidade. $O$ atalho é funcional, pois vincula-se à necessidade humana de fé e crença. Articulado como o elo de uma narrativa totalizante, ele apresenta a resolução do drama que sem atalho seria um impasse. Essa narrativa, marcadamente antropocêntrica e linear, subsome o múltiplo da realidade a um modelo de identidade e anula o próprio patamar de variação da imaginação. Já o caráter totalizante a ela associado deposita-se nas formas lógicas ou ideais que orbitam em torno do homem ocidental, europeu, branco, urbano e heterossexual. Hoje, estamos diante da dupla tarefa de divisar as consequências nocivas relacionadas aos efeitos desse atalho e de procurar modos de desarmá-las.

$\mathrm{O}$ atalho evolucionista possui parentesco em primeiro grau com outro dispositivo que nos cumpre apresentar: o dualismo. Por meio da cisão entre corpo e alma, criamos um modelo de cientificidade 
simétrico à narrativa evolucionista. $\mathrm{O}$ dualismo impregnou nossos modos de inteligibilidade, balizando os limites da compreensão do real e das experiências atinentes à subjetividade humana. Tais limites, contestados e afrontados desde o seu princípio por todas aquelas ações discursivas que o ocidente não quis ${ }^{15}$, encontram-se, hoje, mais do que nunca, em xeque. A inoperância da distinção axial e epistemologicamente intransponível entre fenômenos naturais e constructos sociais, por exemplo, impede de pensar os fenômenos híbridos que proliferam na nossa atualidade, atravessando constantemente o esquematismo asséptico da "Grande Divisão que nos separa tanto de nosso passado quanto dos outros coletivos" (LATOUR, 2013, p. 56). Trata-se aqui de apontar que tais scripts de pensamento criam determinados limites para o que somos capazes de ver e dizer e para aquilo que escapa aos nossos sentidos. Daí surgem bloqueios, elevados sob a forma de imperativos, pelo menos desde Kant, criados para evitar o mergulho do pensamento em seu tecido inteiriço. São esses limites que impõem uma determinada imagem ao nosso pensamento e é contra eles que pretendemos pensar elementos para uma aula de História não-narcísica.

Eis que devemos agora particularizar o rumo de nossas indagações e de pronto perguntar: o que o atalho epistemológico e seus dispositivos conexos aportam diretamente ao modo de funcionamento da narrativa histórica? Quais são as regularidades enunciativas, mecanismos operatórios e disposições intelectuais que eles incitam ou imprimem a uma sala de aula? Em relação a que tipo de práticas e discursos esses atalhos estabeleceram sua funcionalidade? O que eles excluem e o que deixam ver e dizer? O que querem tais atalhos em uma sala de aula de História? Parece-nos, inicialmente, que a aderência da sala de aula a tais dispositivos não tem a ver com aquilo que chamamos tradicionalmente de "conteúdo" ou "matéria". Tudo se passa como se a aderência da narrativa ao evolucionismo e ao dualismo visasse, antes, à preservação de uma certa mise-en-scène pedagógica. A mise-en-scène, ou aquilo que poderíamos chamar de uma certa "ordem do discurso pedagógico" (LARROSA, 2015), caracteriza-se pela sacralização (sacro no sentido em que não está sujeito à dúvida ou contestação) de alguns elementos fundamentais que funcionam como axiomas de base. O respeito reverencial pela forma lógica e pelas relações de causa e efeito, por exemplo, indicam que uma aula de História deve possuir uma aparência de explicação. Ao confundir-se com a própria forma da explicação, o que uma aula de História produz? O que ela dissipa e perde? Que tipo de relações com o conhecimento, os saberes, o corpo e a linguagem ela provoca e estimula?

Esse duplo adquire também aspectos notadamente epistemológicos, pela dualidade explícita, ao que aparentemente professores são incapazes de abandonar, entre uma matéria empírica, ainda revivida nos fatos, e uma imaginação histórica, como a operação da inteligência de onde resultam as explicações históricas. Esse duplo é o que, em verdade, ainda mantém fora da sala a ética e a política, uma vez que ainda hoje parece esfumaçar a pretensão cientificista da História disciplinada e da aula de História. Ele repercute o medo da própria hesitação, pois, sob o signo da hesitação, precisamos admitir que os fatos possuem uma vida dupla, uma imagem bifacial, eles são, simultaneamente, empíricos e transcendentais. $O$ erro das abordagens relativistas consiste em crer que diante dos fatos encontramos apenas a face transcendental, disponível irrestritamente aos esforços elásticos do imaginário. Já o equívoco dos argumentos que apelam à intransigência de um racionalismo reativo e positivista consiste em arvorar a explicação histórica na hipertrofia da tendência contrária, ou seja, nesse caso os fatos possuiriam uma existência exclusivamente empírica. O que ocorre é que o fato sem a imaginação, assim como a imaginação sem o fato, não chegam a fazer sentido. O sentido se faz nos giros e acoplamentos inevitáveis entre o empírico e o transcendental, ele jamais está dado como algo a ser descoberto e para sempre

\footnotetext{
${ }^{15}$ A “regulação aristotélica da linguagem" em torno da “decisão do sentido" cria um liame lógico, pragmático e transcendental que exclui do campo racional e da humanidade todos os discursos que não preenchem as condições de significação. No interior do próprio corpus ocidental, pode-se identificar uma série de discursos e movimentos, como a sofística, o orfismo, o estoicismo e o epicurismo, por exemplo, que são postos à margem do cânone pelo gesto aristotélico (conforme CASSIN, 2005, p. 135). Muitos séculos depois, o aristotelismo prosélito do Padre Antônio Vieira efetua o mesmo gesto em relação às práticas e crenças dos nativos americanos (conforme VIVEIROS DE CASTRO, 2013, p. 184-185). Por via desses mecanismos ontológicos excludentes, produtores de margens inumanas (não) filosóficas, entende-se que "o princípio metafísico do colonialismo coincide com o princípio colonialista da metafísica” (SILVA, 2014, p. 110).
} 
afixado. Tanto o relativismo irresponsável quanto o cientificismo de tribunal perdem o contato com o sentido da coisa histórica ao se fixarem em apenas uma de suas vidas.

Esse medo da própria hesitação diante do duplo é o que ainda nos mantém na malha narcísica, nem nos deixando mergulhar na imanência da matéria, nem fazendo da aprendizagem uma espécie de arte capaz de simpatizar com o real (BERGSON, 2010a). A teia da aranha parece ser, então, algo intransponível. Mas a sala de aula não é somente um espaço-temp(I)o asséptico, passivo-fenomênico, onde subdividemse os corpos precários de indivíduos separados (ficção da nossa modernidade filosófica) e a alma categorial organizadora de um mestre aristotélico (o professor). E a História não é somente essa ciência bem comportada e branca, ao menos não mais, que se contorce entre o empírico, o fato cru e bruto, e o transcendental, a linguagem, perspectiva, intérprete e relativa.

A dimensão da sala de aula que vislumbramos aqui é aquela que se apresenta como o espaço tentacular de um corpo coletivo, intrincado, labiríntico, híbrido, verdadeiro ninho de aranhas marcado por trocas infinitesimais de afetos e sensações e pela elasticidade dos nexos pré-individuais (o que torna um espaço verdadeiramente público é o fato de que ali ainda não existem indivíduos, mas individuações em estado larvar). Essa sala de aula não se divide entre corpos (os alunos) e espírito (o professor), pois possui o dinamismo tentacular aracnoide de uma alma coletiva. Isso não quer dizer que ela se assemelhe a um protótipo idealizado, transcendente ou inefável, mas que sua singularidade é abrir um terreno escorregadio aos sentidos. A teia se faz e desfaz, aparece e desaparece, conforme o lance contingente dos efeitos reflexos que cruzam a sala, tecido de uma realidade trêmula, experimentada a cada vez pelas forças que passam por corpos interconectados (daí que diante de tais nuances situar tão facilmente algo como "realidade do aluno" soe-nos como um atalho, uma batida de carteira epistemológica). Trata-se assim do campo onde uma grande sensório-motricidade partilhada -a matéria, livre das operações de reificação do indivíduo, é um campo infinito de imagens (BERGSON, 2010b) -experimenta fluxos de retração e expansão, contração e exasperação, euforia, ansiedade e angústia. Nessa sala de aula não há vitória de um espírito analítico sobre os instintos repulsivos de um corpo dominado. Nela, o que ocorre é que o gosto e o cuidado especiais com a matéria nos levam a um grau extremo de atenção ao que acontece. Atenção à realidade, à vida, e às ínfimas variações manifestadas a cada vez que o sentido é tocado por um movimento, um gesto ou simplesmente rasgado pela voz rouca de um professor exasperado.

Do mesmo modo, essa Aula Tentacular (doravante AT), que acredita tanto na multiplicidade do fato bruto, quanto na arte da imaginação histórica, abre um campo de relações com o passado, do qual a inteligência, que cria as explicações e compõe os dados dando os contornos de uma narrativa, é apenas um dos elementos compósitos que circulam, labirintizam e se interpenetram. Nessa AT, forças vêm de todos os lados, do fato cru e bruto, da matéria a ser ensinada, das narrativas que se avolumam, históricas, míticas, das vidas dos alunos, das vidas dos docentes, das vidas que, sem mediação explicativa, entram em um salto nessa AT, com a pergunta inusitada de um estudante: "Professora, o povo Yanomami não está sendo dizimado, no Brasil, não é?"

O silêncio que se segue à pergunta do aluno não é uma falta de barulho, mas um silêncio tanto em relação ao fato (Yanomamis/dizimação) quanto à narrativa (proposição/sentido: a verdade afirmada sobre o que acontece com os Yanomamis, hoje, no Brasil). Trata-se da própria hesitação diante tanto da inviolabilidade do fato, quanto da arte da narrativa. É esse formigamento que faz da AT uma teia onde tudo estremece ao mesmo tempo, desacomodando os lugares que estabelecemos, com nossos antropologismos estéticos, para cada coisa, seja da matéria, seja da linguagem. Sobretudo, porque a pergunta do aluno pouco reconhece esse duplo de que viemos falando desde o início e que tem atormentado historiadores e professores de História. Mas o professor sim, o reconhece, e por reconhecêlo, tem a oportunidade, se estiver à espreita, de preparar a armadilha, avivar as perspectivas em jogo, percorrer o ilimitado do sentido no mistério da colisão entre o empírico e o transcendental, problematizar o que se diz sobre o povo Yanomami, imaginar como teria sido a vida desse povo se europeus nunca tivessem aportado aqui ou, ainda, imaginar como os Yanomami têm pensado suas relações com os homens brancos e com a floresta (KOPENAWA; ALBERT, 2015). "Rapidamente, um período histórico 
passa a dar a impressão de uma grande montagem. Ao invés de um belo fluxo laminar, frequentemente teremos um fluxo turbulento de turbilhões e corredeiras" (LATOUR, 2013, p. 72).

Sob o signo da hesitação, o narcisismo cede o passo para expor e mostrar a nudez de uma relação intensa entre a linguagem, a teia e os estilhaços. Antes de uma predicação, é de um formigamento que falamos e, assim, de uma certa "falta de jeito", daquilo que Deleuze dizia ser a grandeza mínima atinente à heterogeneidade. $\mathrm{E}$ é aí que o tempo nos convoca para sua morada eterna. O eterno acontecimento que se desloca da fadiga do duplo empírico-transcendental e nos joga na infinidade do sentido. Para pensar, contra a temporalidade evolutiva e progressivista, uma aula de História não narcísica, será necessário abandonar as marcas temporais, as temporalizações, as medições todas, para flertar com o tempo em sua crua e brutal neutralidade. Aí poderemos pensar que passado, presente e futuro não são necessariamente sucessivos. Desse modo, poderemos abrir possibilidades de tentacular o próprio tempo, seja por tradução, seja por experiência, encontrar com o tempo do outro, sem jogá-lo contra o nosso espelho narcísico. Estirado por entre as teias, de matéria até mesmo mais fina do que elas, o tempo se faz o puro cristal de imagens ${ }^{16}$ que refletido no espelho deixa-nos entrever o trabalho de aranha da razão.

Eis a Aula-tentacular em pleno desdobramento. Uma rebelião do tempo contra as temporalizações que fazemos dele. Uma rebelião de uma filosofia da multiplicidade contra os duplos que sustentam e justificam a unidade do sujeito. Uma ética que fundamenta a aprendizagem como um trabalho de si sobre si mesmo, diante dos fatos e dos sentidos que produzimos sobre o passado.

O professor F. novamente entrou em sala de aula, armado, como sempre, do seu bloquinho de anotações e de uma caneta dessas que não se compra facilmente em qualquer papelaria. Desta feita, a matéria da aula já anunciava um buraco no tempo: vinha do presente, mas também flertava com o passado e, sobretudo, clamava pelo direito a ter futuros. Era uma aula sobre LGBTQI+s, seus movimentos e sua história. $O$ início foi concomitante a um certo tremor, os dois alunos, Douglas e Marcus ${ }^{17}$ hesitavam. Não exatamente em razão do tema escolhido para a aula, mas diante do livro didático que se anunciava e se insinuava a querer mostrar quem sabe a Revolução Francesa e suas causas ou mesmo o Brasil Colônia e as etapas da colonização. Foi essa hesitação que certamente levou os dois a provocarem os alunos com um jogo de perguntas e respostas (isso tudo "roubado" gentilmente da Dissertação da Muriel'18), onde personagens Marcelo e Raquel eram colocados frente à situações em que os alunos eram levados a escolher o comportamento de cada um, evidentemente relacionado às suas memórias a respeito das relações de gênero. Então, a primeira pergunta jogou Marcus e Douglas numa euforia e numa alegria que somente os bons encontros permitem. Ao perguntar: numa situação de perigo, quando um homem alto, com terno $e$ gravata, branco, se aproxima ofegante com uma arma de grosso calibre anunciando um assalto, Marcelo e Raquel agiriam de que modo? Os alunos deveriam associar as alternativas de respostas a cada um dos dois. a) Foge gritando com muito medo; b) Age calmamente tentando apaziguar a situação; c) Desmaia diante do assaltante; d) Com coragem enfrenta a situação e desarma o homem. Na expectativa de que os alunos denunciassem ali seus supostos preconceitos de gênero, associando as atitudes mais desesperadas à Raquel e as mais racionais à Marcelo, Douglas e Marcus veem o buraco que eles mesmos haviam criado no currículo daquela aula de História, afundar ao infinito, quando os alunos, sem exceção, desvendam a armadilha a eles preparada e dizem que não aceitam e não acreditam que uma mulher seja sempre a desesperada e o homem

\footnotetext{
${ }^{16}$ Um cristal de imagem é o que ocorre quando a percepção é desligada da ação e os prolongamentos motores dão lugar a uma relação de indistinção entre uma imagem atual e uma imagem virtual. Nesse ponto, anti-narcísico por excelência, "[...] dir-se-ia que a imagem atual e sua imagem virtual cristalizam. É uma imagem-cristal” (DELEUZE, 2001, p. 71).

17 Olhar sobre uma aula de História que aconteceu em uma escola da cidade de Viamão, RS. Os dois estudantes de História, Marcus Ribas Moreira e Douglas Bandeira Ramos, realizavam estágio em Ensino Fundamental, disciplina obrigatória da formação docente, e autorizaram o uso da cena aqui descrita.

18 FREITAS, Muriel Rodrigues de. Camilles, pierinas e eunices - condenadas pela razão: mulheres, loucura, documentário e ensino de história. 2016. Dissertação (Mestrado Profissional em Ensino de História) - Programa de Pós-Graduação em Ensino de História, Universidade Federal do Rio Grande do Sul. Porto Alegre: UFRGS, 2016. Disponível em: http://hdl.handle.net/10183/188197http://hdl.handle.net/10183/188197. Acesso em: 06 jun. 2020.
}

Rev. Espaço do Currículo (online), João Pessoa, v.13, n.Especial, p. 753-767, dez. 2020. 
ISSN 1983-1579

Doi: 10.22478/ufpb.1983-1579.2020v13nEspecial.53988

http://periodicos.ufpb.br/ojs2/index.php

sempre o racional.

O tempo em sua completa insensatez, numa pureza quase insuportável. Sem sucessão, sem linha, sem cronologia. Era o acontecimento em seu recuo contínuo mostrando uma abertura ao futuro, sem antecipálo, sem criar mecanismos de adivinhação ou projeção, mas numa crueza que somente a intuição é capaz de experimentar. Um futuro experimentado, um passado (o do preconceito e da discriminação) hesitante e um presente trêmulo, problematizado, desviado da rota. Ali, de uma só vez, o preconceito havia passado como fato, mas sem passar, como insistência que faz lembrar e manter a energia da resistência, como elemento que precede e anuncia não um futuro determinado, mas a possibilidade de se poder imaginar outros futuros: sem discriminação, sem preconceito, sem genocídio e, por fim, sem o espelho narcísico.

A Aula-Tentacular deixa jorrar a multiplicidade do fato bruto, a matéria da aula, e também a arte da imaginação histórica. Ali as forças antes inauditas saltaram para se deixar ver e criar, num jogo que vai da criação estratégica de Marcus e Douglas, passando pelo tema escolhido, até a incontrolável problematização dos estudantes.

F., atônito e esperançoso, esqueceu-se do bloquinho e da caneta, nada anotou, ficou a experiência corporal daquela aula.

\section{CONSIDERAÇÕES FINAIS - A PATILHA DO NÃO-SENTIDO INICIAL}

Depois de atravessar o conjunto de turbulências teórico metodológicas envolvidas neste ensaio, voltamos a nos perguntar, à título de encerramento, o que ocorreu aos pressupostos da aula, e nisso incluímos não apenas a justificativa social da sua existência, mas também o seu influxo de sensações partilhadas, quando a decisão do sentido não foi arbitrariamente tomada desde o início? Parece-nos que o sentido, espreitado como uma bolha de tempo crivada pela hesitação, está sempre por nascer, crescer, explodir como um saco de esporos, pois o seu golpe ou o seu salto, por assim dizer, não pode ser antecipado. Cria-se assim uma espécie de afasia geral, um recuo estratégico, uma reserva intensiva, aparadigmática, por onde correm todas as apostas e expectativas não-totalitárias sobre o que pode ser uma aula, ou melhor, sobre o devir de uma aula qualquer quando ela se torna AT. É nesse (não) lugar, atópico, aporético, paradoxal, que começamos a aprender/ensinar. Mantivemo-nos atentos aos efeitos contingenciais gerados pelo enredo de linhas interrompidas, teias perceptivas e espelhos estilhaçados. Arriscamos suspender o acordo entre o bom senso e o senso comum que força os possíveis da comunicação à violência de um metadiscurso partilhado. Nessas condições, que procuramos explorar ao longo deste ensaio, a experiência do tempo é o que se insinua pela patilha ética de um não-sentido inicial. Falamos então da brecha do acontecimento Deus ou LGBTQI+s, da perplexidade do professor F., da fissura por onde o peso das estruturas narrativas se desgastam até assumir a trivialidade de uma fala qualquer. $\mathrm{O}$ qualquer aqui não como o sem qualidade, mas, precisamente, como a qualidade infra ordinária do que é comum, do que iguala, ou melhor, produz a cada vez o não-sentido consubstancial à igualdade. A igualdade, não somente em termos políticos, mas linguísticos e identitários, só é pensável a partir da patilha radical de um não-sentido inicial. Do contrário, estamos sempre a recitar Parmênides; e o poema da aula já é sempre necessariamente uma citação mais ou menos consciente do Poema do Ser. Começar e concluir pelo não-sentido não é uma irresponsabilidade, mas um exercício ético de liberdade, uma estratégia didático-pedagógica para desfazer o gatilho epistemicida que a ontologia nos deixou.

Sem compreender a tensão que estrutura sua própria narrativa, o Ensino de História torna-se epistemologicamente incapaz de pensar os terceiros, todas as figuras possíveis de "outros" inclusos que forçam as fronteiras do pensamento para fora da ontologia e do seu gesto conexo de captura temporal. Talvez não sejamos capazes de falar, nem mesmo de pensar pelos outros, mas o que podemos fazer é perceber as tensões constitutivas que articulam nosso discurso, carregando a hesitação como antídoto à violência metafísica e marca ética do acolhimento.

\section{REFERÊNCIAS}

AVILA, Arthur Lima de; NICOLAZZI, Fernando; TURIN, Rodrigo (Oorganizadores.). A História (in)disciplinada: teoria, ensino e difusão do conhecimento histórico. Vitória: Editora Milfontes, 2019. 278 
p.

BELLO, Samuel Edmundo Lopez; MARQUES, Diego Souza. Imagens-estilhaçadas: fissuras de um método de pesquisa-aprendizagem. ETD - Educação Temática Digital, Campinas, SP, v. 19, n. 4, p.759-772, out./dez. 2017.

BENJAMIN, Walter. Magia e Técnica, Arte e Política: ensaios sobre literatura e história da cultura. São Paulo: Editora Brasiliense, 1996.

BERGAMASCHI, Maria Aparecida; GOMES, Luana Barth. A Temática Indígena na Escola: ensaios de educação intercultural. Currículo sem Fronteiras, Lisboa; Porto Alegre, v. 12, n. 1, p. 53-69, jan./ abr. 2012.

BERGSON, Henri. A evolução criadora. Trad. Adolfo Casais Monteiro. São Paulo: Ed. UNESP, 2010a.

BERGSON, Henri. Matéria e memória: ensaio sobre a relação do corpo com o espírito. São Paulo: Editora WMF Martins Fontes, 2010b.

BIANCO, Giuseppe. Gilles Deleuze Educador: sobre a pedagogia do conceito. Revista Educação e Realidade, v. 27, n. 2, p. 179-204, jul./dez. 2002.

BRÉHIER, Émile. A teoria dos incorporais no estoicismo antigo. Trad. Fernando Padrão de Figueiredo e José Eduardo Pimentel Filho. Belo Horizonte: Autêntica Editora, 2012.

CASSIN, Barbara. O efeito sofístico: sofística, filosofia, retórica, literatura. Trad. Ana Lúcia de Oliveira, Maria Cristina Franco Ferraz e Paulo Pinheiro. São Paulo: Ed. 34, 2005.

DELEUZE, Gilles. Conversações. Trad. Peter Pál Pelbart. $3^{\text {a }}$ edição. São Paulo: Editora 34, 2013.

DELEUZE, Gilles. Logique du sens. Paris: Les éditions de minuit, 2015.

DELEUZE, Gilles; GUATTARI, Félix. O que é a filosofia? Rio de Janeiro: Ed. 34, 2010.

GIL, José. Caos e ritmo. Lisboa: Relógio D’Água Editores, 2018.

HARTOG, François. Regimes de historicidade: presentismo e experiências do tempo. Belo Horizonte: Autêntica Editora, 2013.

HISTÓRIA: ensino fundamental. Coordenação: Margarida Maria Dias de Oliveira. - Brasília: Ministério da Educação, Secretaria de Educação Básica, 2010. 212 p.: il. (Coleção Explorando o Ensino; v. 21).

KOPENAWA, Davi; ALBERT, Bruce. A queda do céu: palavras de um xamã yanomami. Trad. Beatriz PerroneMoisés; Pref. Eduardo Viveiros de Castro. São Paulo: Companhia das Letras, 2015.

LARROSA, Jorge. Tremores: escritos sobre experiência. Trad. Cristina Antunes, João Wanderlei Geraldi. Belo Horizonte: Autêntica Editora, 2015.

LATOUR, Bruno. Jamais fomos modernos. $3^{\text {a }}$ e. Ed. São Paulo: Editora 34, 2013.

LYOTARD, Jean-François. O Inumano. Lisboa: Editorial Estampa, 1997.

MASSCHELEIN, Jan; SIMONS, Maarten. Em defesa da escola: uma questão pública. Trad. Cristina Antunes. Belo Horizonte: Autêntica Editora, 2013.

MEINERZ, Carla Beatriz; CAIMI, Flávia Eloisa; OLIVEIRA, Sandra Regina. F. O Improvável na Aula de História: sociabilidades, racialidades e modos de estar junto na escola. Revista Pedagógica, Chapecó, v. 20, n. $45, \quad$ p. 53-72, set./dez. 2018. Disponível em: https://bell.unochapeco.edu.br/revistas/index.php/pedagogica/issue/view/267. Acesso em: 01 dez. 2019. DOI-COD: http://dx.doi.org/10.22196/rp.v20i45.4486

MELIÀ, Bartolomeu. A terra sem mal dos Guarani. Revista de Antropologia, v. 33, p. 33-46, 30 dez. 1990. Disponível em: http://www.revistas.usp.br/ra/article/view/111213. Acesso em: 05 fev. 2020.

MONTEIRO, Ana Maria F. C.. A história ensinada: algumas configurações do saber escolar. REVISTA HISTÓRIA \& ENSINO, Londrina, v. 9, p. 09-35, out. 2003. Disponível em: http://www.uel.br/revistas/uel/index.php/histensino/article/view/12075/10607. Acesso em: 05 dez. 2019. 
MOURA, Carla de. As Marias da Conceição: por um ensino de história situado, decolonial e interseccional. 2018. Dissertação (Mestrado em História) - Programa de Pós-Graduação em Ensino de História, Universidade Federal do Rio Grande do Sul. Porto Alegre: UFRGS, 2018.

MOURA, Rosana Silva de. A interpretação da estética da infância em Rousseau e Benjamin. Revista contrapontos [eletrônica], v. 14, n. 1, p. 220-233, jan./abr. 2014, p. 220-233. Disponível em: https://siaiap32.univali.br/seer/index.php/rc/article/view/5032. Acesso em: 14 jul. 2020.

NADAI, Elza Nadai; LAGOA, Ana. História: o bonde que a escola perdeu. Revista Nova Escola. São Paulo: Abril, n. 53, p. 16, nov. 1991.

NEYRAT, Frédéric. Occupying the future. In: WITZGALL, Susanne; STAKEMEIER, Kerstin. The presente of the future. Zurich: Diaphanes AG, 2018. p. 79-90.

NIETZSCHE, Friedrich. A gaia ciência. São Paulo: Companhia das Letras, 2001.

NIETZSCHE, Friedrich. Aurora: reflexões sobre os preconceitos morais. Trad. Paulo César de Souza. São Paulo: Companhia das Letras, 2004.

PEREIRA, Júnia Sales. Do Colorido a Cor: o complexo identitário na prática educativa. In: GONÇALVES, Marcia de Almeida et al. (Org.). Qual o Valor da História Hoje? Rio de Janeiro: FGV, 2012. p. 306-322.

PEREIRA, Mateus H. F.; ARAUJO, Valdei Lopes de. Reconfigurações do tempo histórico. Revista da Universidade Federal de Minas Gerais, v. 23, n. 1 e 2, p. 270-297, 5 jun. 2017.

PEREIRA, Nilton Mullet. O que se faz em uma aula de História? Pensar sobre a colonialidade do tempo. Revista Pedagógica, Chapecó, v. 20, n. 45, p. 16-35, set./dez, 2018. Disponível em: file:///C:/Users/nilton/Downloads/4512-16596-1-PB\%20(15).pdf. Acesso em: 05 maio 2019. DOI-COD: http://dx.doi.org/10.22196/rp.v20i45.4512.

PRADO JR., Bento. Erro, ilusão, loucura: ensaios. São Paulo: Ed. 34, 2004.

RAMOS, Douglas Bandeira; MOREIRA, Marcus Ribas. Relatório de Estágio de Docência em História. Ensino Fundamental. Disciplina EDU 2088, ESTÁGIO DE DOCÊNCIA EM HISTÓRIA - ENSINO MÉDIO (2019/02). Universidade Federal do Rio Grande do Sul, 2019.

SETH, Sanjay. Razão ou raciocínio. Clio ou Shiva? História da historiografia, Ouro Preto, n. 11, p.173-189, abril 2013.

SILVA, Cleber Daniel Lambert da. Deleuze e Bergson: tensão, esforço e fadiga na instauração filosófica. 2014. Tese (Doutorado em Ciências Humanas) -- Programa de Pós-Graduação em Filosofia, Universidade Federal de São Carlos. São Carlos: UFScar, 2014. $251 \mathrm{f}$.

TADEU, Tomaz; CORAZZA, Sandra; ZORDAN, Paola. Linhas de escrita. Belo Horizonte: Autêntica, 2004. 208p.

VIVEIROS DE CASTRO, Eduardo. A inconstância da alma selvagem e outros ensaios de antropologia. 5 ed. São Paulo: Cosac Naify, 2013.

VIVEIROS DE CASTRO, Eduardo. Metafísicas canibais: elementos para uma antropologia pós-estrutural. São Paulo: Cosac Naify, 2015.

ZUMTHOR, Paul. Performance, recepção, leitura. Trad. Jerusa Pires Ferreira e Suely Fenerich. São Paulo: Cosac Naify, 2014.

Recebido em: 16/07/2020

Aceito em: 08/10/2020

Publicado em: 11/12/2020 